\title{
Model Sistem Perparkiran Kendaraan di Bandar Udara Sentani Jayapura
}

\author{
Johanis Taran*1, Sakti Adji Adisasmita ${ }^{1}$, Mubassirang Pasra ${ }^{1}$ \\ ${ }^{1}$ Departemen Teknik Sipil, Fakultas Teknik, Universitas Hasanuddin, Makassar \\ Jl. Poros Malino km. 6, Bontomarannu, Kabupaten Gowa, Sulawesi Selatan 92171 \\ *Email: johanistaran@gmail.com
}

DOI: 10.25042/jpe.112018.06

\begin{abstract}
Abstrak
Penelitian ini bertujuan untuk mengetahui karakteritik kondisi eksisting, persepsi responden pengguna lahan parkir, dan kebutuhan ruang parkir berdasarkan tingkat akumulasi tertinggi. Metode pengumpulan data dilakukan dengan cara survei langsung ke lapangan untuk mencatat jumlah dan waktu kendaraan saat masuk dan keluar serta survei persepsi responden pengguna parkir dengan menggunakan kuisioner. Hasil analisis data memperlihatkan bahwa bahwa rata-rata volume kendaraan perhari adalah sebesar 2649 dengan akumulasi rata-rata tertinggi adalah sebesar 639. Durasi kendaraan rata-rata perhari adalah 1,65 kendaraan/jam, nilai parking turn over rata-rata sebesar 6 dan indek parkir sebesar 1,48\%, hal ini berarti bahwa rata-rata perhari hanya 6 kendaraan yang bergantian menempati 1 ruang parkir. Angka pergantian parkir yang rendah ini disebabkan karena volume kendaraan sangat tinggi dengan durasi parkir cukup lama namun ruang parkir yang tersedia sangat kurang yakni sebanyak 432 ruang parkir, sehingga berdampak pada over kapasitas parkir yang dapat dilihat dari tingginya angka akumulasi parkir yang terjadi pada jam puncak yaitu pada pukul 12.30-13.00 wit. Dari 313 responden pengguna parkir yang memberikan tanggapan terhadap 16 parameter tentang karakteristik lahan parkir, 5\% menyatakan sangat layak, 23\% menyatakan layak, 57\% menyatakan kurang layak, 11\% menyatakan buruk, dan 5\% menyatakan sangat buruk. Model kebutuhan ruang parkir menunjukan adanya hubungan antara volume kendaraan dan akumulasi sebesar $\mathrm{R}=0,67$ dengan model $\mathrm{y}=0,06972 \mathrm{x}+454,07$, Kapasitas dan akumulasi sebesar $\mathrm{R}=0,62$ dengan model $\mathrm{y}=0,0696 \mathrm{x}+$ 454,07 , Durasi dan akumulasi sebesar $\mathrm{R}=0,60$ dengan model $\mathrm{y}=-91,72 \mathrm{x}+789,49$.
\end{abstract}

\begin{abstract}
Model of Vehicle Parking System at Sentani Airport, Jayapura. This study aims to determine the characteristics of existing conditions, the perceptions of respondents of parking users, and the need for parking space based on the highest accumulation rate. Methods of data collection is done by direct survey to the field to record the number and time of the vehicle when entering and exiting and survey the perception of respondents parking users by using questionnaires. The result of data analysis shows that the average daily vehicle volume is 2649 with the highest average accumulation is 639.Average vehicle duration per day is 1.65 vehicles/hour,average parking turn over value of 6 and parking index of $1.48 \%$, this means that on average per day only 6 vehicles alternately occupy 1 parking space.Low parking turnover is due to the very high vehicle volume with a long parking duration but parking space available is very less ie as many as 432 parking spaces, so that the impact on over-capacity parking that can be seen from the high number of parking accumulation that occurred at the peak hour is at 12:30 to 13:00 pm. From 313 respondents of parking users who responded to 16 parameters about the characteristics of parking lots, 5\% stated very worthy, $23 \%$ stated feasible, $57 \%$ said it was not feasible, $11 \%$ expressed bad, and 5\% said very badly. The model of parking space needs shows the relationship between vehicle volume and accumulation of $\mathrm{R}=0.67$ with the modely $=0.06972 \mathrm{x}+454.07$, Capacity and accumulation of $\mathrm{R}=$ 0.62 , with the model $y=0.0696 x+454.07$, Duration and accumulation of $R=0.60$ with the model $y=-91.72 x+789.49$.
\end{abstract}

Kata Kunci: Akumulasi, durasi, karakteristik, model regresi, parkir

\section{Pendahuluan}

Sebagai satu-satunya bandar udara yang melayani tiga kabupaten/kota disekitarnya maka Bandar Udara Sentani merupakan salah satu bandar udara yang memiliki aktifitas terpadat di Provinsi Papua karena selain melayani transportasi penumpang, Bandar Udara Sentani juga melayani transportasi barang (kargo udara). Berdasarkan data, jumlah penumpang tahun 2010 berjumlah 1.080 .927 penumpang dan pada tahun 2014 berjumlah 1.546 .848 penumpang [1], sehingga tiap tahunnya rata-rata Tingkat 
Pertumbuhan Tahunan-nya (Average Annual Growth Rate) mencapai 9,74\%. Sedangkan jumlah penumpang dalam perhari berdasarkan data dari Direktorat Jenderal Perhubungan Udara berjumlah rata-rata perhari mencapai 2600 sampai 2700 penumpang perhari sedangkan untuk waktuwaktu libur mengalami lonjakan hingga $20 \%$ atau mencapai 3500-an penumpang perhari [1].

Dengan banyaknya peminat dalam menggunakan transportasi udara, maka pihakpihak yang terkait seperti perusahaan penerbangan, dan pengelola bandar udara dituntut harus memaksimalkan pelayanan kepada pengguna transportasi udara, baik dari segi sarana maupun prasarana angkutan udara. Fasilitas parkiran kendaraan pada bandar udara merupakan salah satu sarana penting dalam menunjang kelancaran pelayanan transportasi udara, dimana menurut Keputusan Dirjen Perhubungan Udara Nomor : SKEP/77/VI/2005 tentang Persyaratan Teknis Pengoperasian Fasilitas Teknik Bandar Udara, bila jumlah kendaraan yang parkir lebih dari 1.200 kendaraan perhari yang diukur berdasarkan jumlah penumpang waktu sibuk perhari antara 501 sampai 1.500 penumpang maka luas area parkir minimal $17.535 \mathrm{~m}^{2}$ [2].

Dengan demikian bila dibandingkan dengan kondisi eksisting saat ini dimana area parkir kendaraan pada Bandar Udara Sentani Jayapura hanya memiliki luas keseluruhan $\pm 4000 \mathrm{~m}^{2}$, namun luasan ini sudah mencakup area parkir untuk lokasi droping penumpang, parkir bus bandara dan taxi bandara, maka dapat dikatakan sangat kurang bahkan jauh dari standar yang dipersyaratkan. Dengan kondisi keterbatasan lahan parkir maka berdampak pada ketersediaan ruang parkir kendaraan roda empat hanya terdiri dari 432 SRP, sehingga mengakibatkan over kapasitas parkir pada saat jam puncak akibat dari akumulasi parkir yang tinggi dan durasi parkir kendaraan yang cukup lama menempati ruang parkir yang tersedia.

Kondisi lainnya dilihat dari segi pengembangan atau perluasan lokasi parkiran untuk sementara ini merupakan satu masalah yang tidak mungkin secepatnya dapat direalisasikan karena lokasi parkiran kendaraan Bandar Udara Sentani diapit oleh lokasi perumahan penduduk, perkantoran dan ruko-ruko. Dengan kondisi saat ini, tingkat layanan parkiran kendaraan pada Bandar Udara Sentani jauh dari maksimal, hal ini bertambah parah bila memasuki hari-hari libur yang mana terjadi lonjakan jumlah kendaraan yang akan parkir dibandingkan dengan kapasitas tampung pada area parkiran, sehingga menimbulkan berbagai permasalahan seperti kemacetan dan kesemerautan dilokasi parkiran kendaraan yang mana hal ini tentunya akan berdampak pada tingkat layanan bagi pengguna parkir.

Selain masalah keterbatasan ruang parkir yang tersedia, terdapat pula masalah terkait atributatribut pada lokasi parkir Bandar Udara Sentani Jayapura yang tidak sesuai dengan stadarisasi yang telah ditetapkan oleh dirjen perhubungan tentang perparkiran kendaraan, seperti luas setiap petak parkir, luas modul, luas jalur sirkulasi, luas jalur masuk dan keluar, kerb (pemisah jalur parkir), kurangnya petugas parkir, rambu-rambu kurang terawat, pemeliharaan marka-marka parkir sangat kurang, jarak antara lokasi parkir dan loket pembayaran terlalu dekat sehingga sering terjadi antrian kendaraan yang panjang. Dengan demikian berdampak pada kenyamanan bagi pengguna parkir, seperti kemudahan kendaraan saat melakukan manuver untuk masuk maupun keluar dari petak parkir dan kemudahan saat membuka pintu, hal ini terjadi karena luas petak parkir yang terlalu sempit dan luas jalur gang terlalu sempit. Perilaku parkir juga menjadi masalah karena terdapat banyak pengguna kendaraan yang tidak memarkirkan kendaraannya tepat pada petak parkir yang tersedia sehingga mengakitbatkan berkurangnya kapasitas tampung setiap jalur parkir.

Penelitian ini bertujuan untuk meninjau bagaimana karateristik kondisi eksisting parkiran yang mencakup volume atau jumlah kendaraan yang masuk dan keluar dari lokasi parkir, bagaimana tingkat akumulasi parkir, bagaimana durasi parkir kendaraan dan bagaimana kapasitas parkir yang tersedia. Akan ditinjau pula bagaimana model kebutuhan parkir berdasarkan hubungan antara faktor-faktor yang telah tersebut, selain itu akan dilakukan survei juga untuk mengetahui bagaimana persepsi pengguna parkir 
tentang kondisi eksisting parkiran terhadap tingkat layanan parkir.

\section{Tinjauan Pustaka}

\subsection{Konsep Sistem Perparkiran}

Objek yang digunakan dalam penelitian ini adalah sebuah kapal ikan Pelat Datar berlisensi dengan kapasitas 10 GT. Desain badan kapal ini merupakan sebuah terobosan karena badan / lambung kapal dibuat tanpa ada lekukanpelat samasekali. Badan kapal terbuat dari baja dengan proses pembuatan terbilang singkat, berbiaya murah serta layak digunakan oleh nelayan lokal/tradisional di Indonesia.

Dalam membahas masalah perparkiran, perlu diketahui beberapa istilah penting sebagai berikut:

- Kapasitas Parkir: kapasitas parkir (nyata)/kapasitas yang terpakai dalam satusatuan waktu atau kapasitas parkir yang disediakan (parkir kolektif) oleh pihak pengelola.

- Kapasitas Normal: kapasitas parkir (teoritis) yang dapat digunakan sebagai tempat parkir, yang dinyatakan dalam kendaraan. Kapasitas parkir dalam gedung perkantoran tergantung dalam luas lantai bangunan, maka makin besar luas lantai bangunan, makin besar pula kapasitas normalnya.

- Durasi Parkir: lamanya suatu kendaraan parkir pada suatu lokasi.

- Kawasan parkir: kawasan pada suatu areal yang memanfaatkan badan jalan sebagai fasilitas dan terdapat pengendalian parkir melalui pintu masuk.

- Kebutuhan parkir: jumlah ruang parkir yang dibutuhkan yang besarnya dipengaruhi oleh berbagai faktor seperti tingkat pemilikan kendaraan pribadi, tingkat kesulitan menuju daerah yang bersangkutan, ketersediaan angkutan umum, dan tarif parkir.

- Lama Parkir: jumlah rata-rata waktu parkir pada petak parkir yang tersedia yang dinyatakan dalam 1/2 jam, 1 jam, 1 hari.

- Puncak Parkir: akumulasi parkir rata-rata tertinggi dengan satuan kendaraan.
- Jalur sirkulasi: tempat yang digunakan untuk pergerakan kendaraan yang masuk dan keluar dari fasilitas parkir.

- Jalur gang: merupakan jalur dari dua deretan ruang parkir yang berdekatan.

- Retribusi parkir: pungutan yang dikenakan pada pemakai kendaraan yang memarkir kendaraannya di ruang parkir.

\subsection{Pemodelan Sistem}

Model adalah alat bantu atau media yang dapat digunakan untuk mencerminkan dan menyederhanakan suatu realita (dunia sebenarnya) secara terukur [3, 4], beberapa diantaranya adalah:

- Model fisik (model arsitek, model teknik, wayang golek, dan lain-lainnya).

- Model peta dan diagram.

- Model statistik dan matematik (fungsi atau persamaan) yang dapat menerangkan secara terukur beberapa aspek fisik, sosial ekonomi, atau model transportasi.

Semua model merupakan penyederhanaan realita untuk mendapatkan tujuan tertentu, yaitu penjelasan dan pengertian yang lebih mendalam serta untuk kepentingan peramalan.

\subsection{Sasaran dan Kewenangan Penyelenggaraan} Parkir

Sasaran utama dari penyelenggaraan parkir [5] adalah:

- Untuk mengendalikan jumlah kendaraan yang masuk kesuatu kawasan.

- Meningkatkan pendapatan asli daerah yang dikumpulkan melalui retribusi parkir.

- Meningkatkan fungsi jalan sehingga sesuai dengan peranannya.

- Meningkatkan kelancaran dan keselamatan lalu lintas.

- Mendukung tindakan pembatasan lalu lintas lainnya.

Kewenangan penyelenggaraan parkir [6] adalah :

- Pemerintah.

- Badan hukum Indonesia.

- Warga negara Indonesia. 


\section{Bahan dan Studi Metode}

\subsection{Penentuan lokasi peneltian}

Penelitian ini bertempat di lokasi parkiran kendaraan roda 4 Bandar Udara Sentani Jayapura.

\subsection{Metode pengumpulan data}

Metode pengumpulan data yang digunakan adalah, survei kordon (cordon count) untuk mengumpulkan data primer berupa waktu, nomor plat dan jumlah kendaraan saat masuk dan keluar parkiran. Survei inventarisasi parkir untuk mengumpulkan data primer dan juga data sekunder berupa luas lahan parkir, luas petak parkir, luas gang, luas modul, jalur masuk dan keluar, jalur sirkulasi, pintu masuk dan keluar, rambu-rambu, marka-marka, penanggung jawab dan manajemen pengelolaan parkir. Survei kuisioner untuk mengumpulkan data persepsi responden tentang kondisi eksisting parkiran terhadap tingkat layanannya, dimana model kuisioner terbagi 2 jenis yaitu kuisioner berbentuk fisik yang dicetak dan dibagi kepada pengunjung saat masuk kelokasi parkir, dan kuisioner online yang dikembangkan oleh google (google drive).

\subsection{Pengolahan dan Analisa Data}

Data hasil survei yang terkumpul selanjutnya akan diolah dengan dengan cara melakukan rekapitulasi data menggunakan program microsoft excel.

Sesuai dengan tujuan penelitian maka analisa data yang pertama adalah analisa karakteristik parkir yang meliputi volume kendaraan, akumulasi parkir, durasi, parking turn over, kapasitas parkir, dan indeks parkir. Kedua adalah analisa persepsi responden yang meliputi karakteristik responden, karateristik penumpang/pengunjung, karateristik kendaraan, dan karateristik kondisi eksisting parkiran kendaraan. Ketiga adalah analisa pemodelan kebutuhan parkir yang meliputi model hubungan volume terhadap akumulasi, kapasitas terhadap akumulasi, dan durasi terhadap akumulasi.

\section{Hasil dan Pembahasan}

Gambar 1 menunjukan volume kendaraan perhari mencapai rata-rata diatas 2600 kendaraan, dengan volume tertinggi terjadi pada mencapai diatas 3000 kendaraan. Gambar 2 menunjukan akumulasi perhari mencapai rata-rata diatas 600 kendaraan, dengan akumulasi tertinggi terjadi pada mencapai diatas 677 kendaraan.

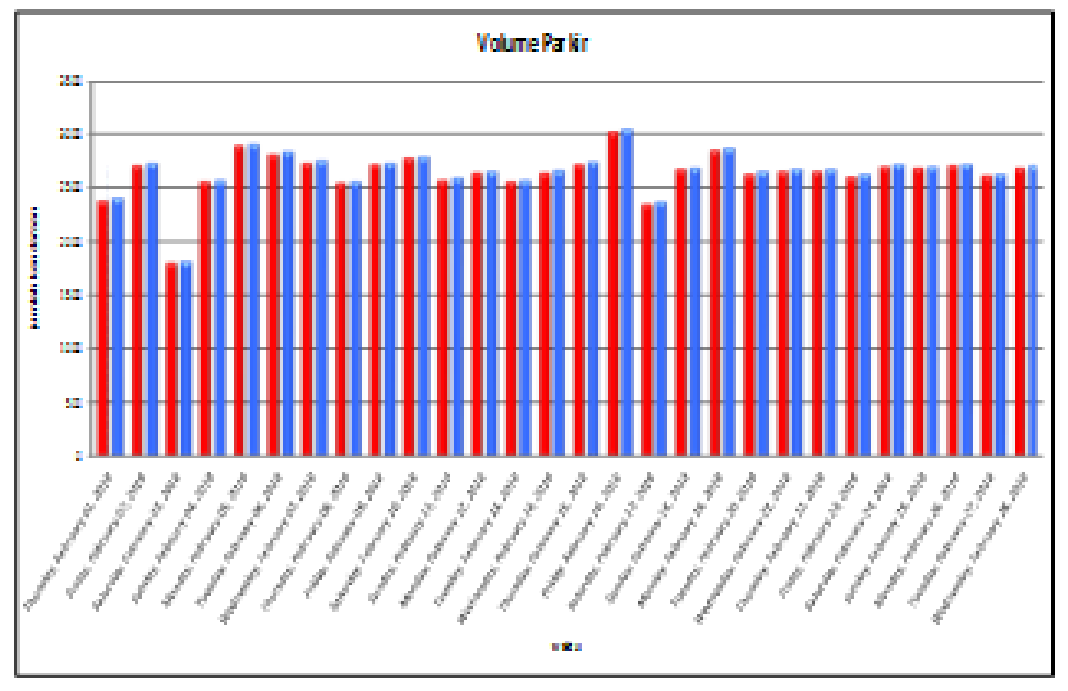

Gambar 1. Volume parkir kendaraan roda 4 


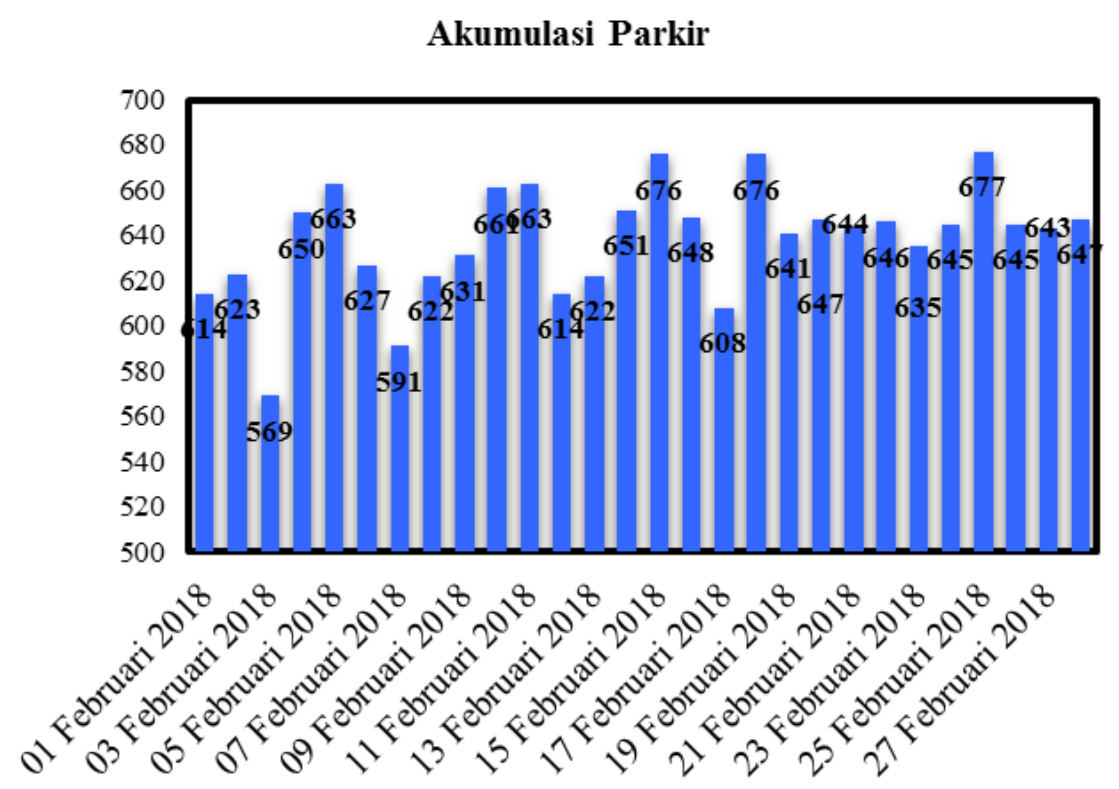

Gambar 2. Akumulasi parkir kendaraan roda 4

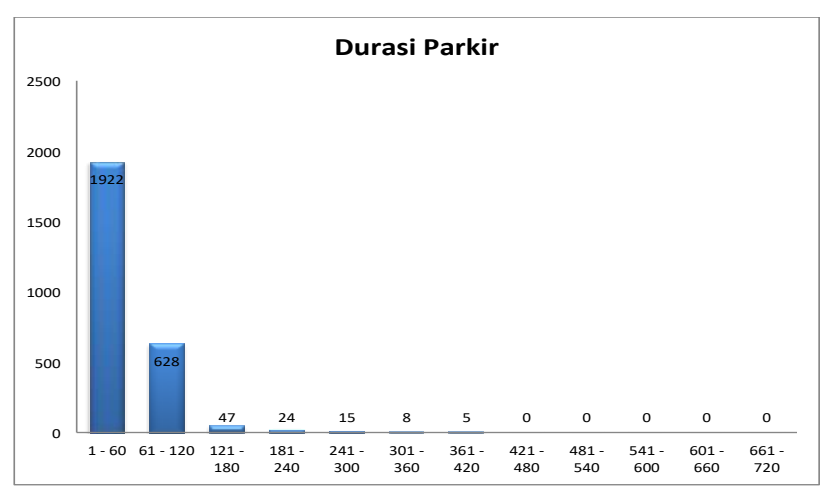

Gambar 3. Akumulasi parkir kendaraan roda 4

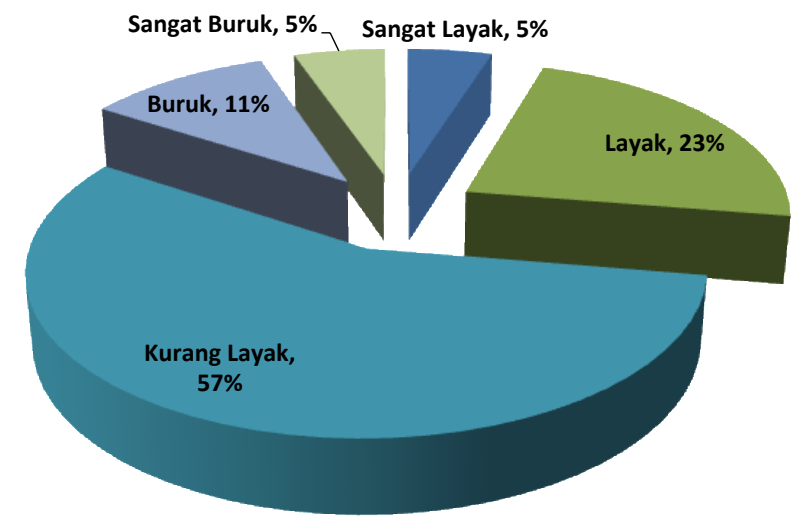

Gambar 4. Persepsi responden

Gambar 3 menunjukan durasi parkir kendaraan terbanyak adalah antara 1-2 jam dan berdasarkan hasil analisa durasi rata-rata adalah $1,37 \mathrm{jam} /$ kendaraan.
Gambar 4 menunjukkan persentase persepsi responden terhadap kondisi eksisting parkiran kendaraan, dimana sebesar 5\% menyatakan sangat layak, 23\% menyatakan layak, 57\% menyatakan kurang layak, $11 \%$ menyatakan buruk, dan 5\% menyatakan sangat buruk.

\section{Kesimpulan}

Berdasarkan hasil analisa dan pembahasan maka dapat ditarik beberapa kesimpulan sebagai berikut: (1) Rata-rata volume parkir kendaraan tertinggi adalah 2649 kendaraan perhari, rata-rata akumulasi tertinggi adalah sebesar 639 kendaraan yang terjadi pada pukul 11.00-12.00 wit. (2) Tingkat pergantian parkir rata-rata adalah 6 kendaraan perpetak yang berarti bahwa dalam selama waktu penelitian (12 jam/perhari) jumlah kendaraan yang menempati satu petak parkir hanya sebanyak 6 kendaraan, indeks parkir adalah $1,48 \%$ dan durasi parkir rata-rata adalah 1,65 kendaraan perjam, dan kapasitas parkir adalah 265 kendaraan perhari. (3) Dari 313 jumlah responden yang memberikan persepsi terhadap kondisi eksisting parkiran kendaraan, maka 5\% menyatakan sangat layak, 23\% menyatakan layak, $57 \%$ menyatakan kurang layak, 11\% menyatakan buruk, dan 5\% menyatakan sangat buruk. 


\section{Referensi}

[1] Dirjen Perhubungan Udara, Statistik Angkutan Udara, 2014.

[2] Departemen Perhubungan Direktorat Jenderal Perhubungan Udara. 2005. "Persyaratan Teknik Bandar Udara", Peraturan Direktorat Jenderal Perhubungan Udara Nomor : SKEP/77/VI/2005".

[3] Ofyan Z. Tamin, 2000, "Perencanaan dan Pemodelan Transportasi".

[4] Ofyan Z. Tamin, 2008, "Perencanaan, Pemodelan, dan Rekayasa Transportasi : Teori, Contoh Soal, dan Aplikasi”.
[5] Direktorat Jenderal Perhubungan Darat, Direktorat Bina Sistem Lalu Lintas Angkutan Kota. 1998. "Pedoman Perencanaan dan Pengoperasian Fasilitas Parkir".

[6] Departemen Perhubungan Direktorat Jenderal Perhubungan Udara. 2005. "Persyaratan Teknik Bandar Udara", Petunjuk Pelaksanaan Pemeliharaan Konstruksi Landas Pacu (Runway), Landas Hubung (Taxiway) dan Landas Parkir (Apron) serta Fasilitas Penunjang Bandar Udara Nomor : SKEP/78/VI/2005". 